\title{
Study of Temperature Rise of Small Brushed DC Motor Under Different Load
}

\author{
N.Fatimah Abdullah ${ }^{1}$, Abbas A.Wahab ${ }^{1}$, M.A.H. Rasid ${ }^{1, *}$ \\ ${ }^{1}$ Faculty of Mechanical Engineering, Universiti Malaysia Pahang, 26600 Pekan, Pahang, Malaysia
}

\begin{abstract}
The heating of brush DC motor in the various applications usually involves the thermal damage to the motor like demagnetization of the magnet and also leads to short circuit. Due to this problem, the temperatures at the sensitive components are needed to be observed for a different number of loads. So, the motor will be delivered some torque when running thus generating the different value of losses. In this paper, a healthy brush DC motor is being used to observed temperature rise from the brush through the motors' component and lastly to the outer space of the motor. Hence, discussion on the pattern of temperature rise will be discussed.
\end{abstract}

\section{Introduction}

Nowadays, there were lots of applications that implement motor as the alternative source. The motors have been used mostly in the industrial field which involving them to operate some machines like the induction motor, DC motor, BLDC motor, PMSM motor and many more. In recent years, DC motor can constantly use in the most famous applications which relate to the process of heating and cooling of the motor. Due to this, using motor vigorously can lead to the thermal behavior problems in the motor itself. The most common irreversible damage done to the motor is thermal damage: melting or burning the winding insulation leading to short-circuiting and demagnetization of the permanent magnet. This can be referred to the Li Yan et. al [1] which presented that, because of high motor internal temperature will precisely weaken the characteristics of permanent magnet materials, the degree of fatigue of the rotor bearing and motor efficiency. Next, usually, this small DC motor is being used widely for low voltage range from 12-24 V.

Recently, most of the literature was concerned about the thermal behavior of the motor especially on the heat transfer of the motor and the heat dissipation. Instead of that, during the motor running, some of the heat losses will dissipate such as copper loss, iron losses, mechanical losses and stray losses. But, this DC motor mainly involves the copper losses and iron losses [1]. The example of the equation in copper losses is as follow;

$$
\mathrm{P}_{\text {copper }}=\mathrm{I}^{2} \mathrm{R}
$$

\footnotetext{
* Corresponding author: mahizami@ump.edu.my
} 
From this equation, the copper losses are proportional to the resistance, $\mathrm{R}$ which this comes from the heat loss of the winding in DC motor. Apparently, this resistance can be relating to the basic principle of the voltage. For the DC source, the speed of a motor is proportional to the voltage, while the torque is proportional to the current as presented in Equation 2.

$$
\mathrm{V}=\mathrm{I} \mathrm{R}
$$

Thus, when the load is increasing, the current also will increase. As a result, more heat losses will generate. Other than that, the optimization problems which always include a coupled thermal-electromagnetic problem are becoming common increasingly between engineers and designers of the machines [2-3]. Hence, the heat transfer in the small DC motor needs to understand. So, the principles of DC motor clearly involve the process of heat transfer. In the previous study, the heat transfer can be divided into three mechanisms [4-6]. All three heat transfer mechanisms of conduction, radiation, and convection occur in the motor (Equation 1, 2 and 3). The equation can be shown as follow;

$$
\begin{gathered}
\dot{\mathrm{Q}}_{\text {cond }}=\frac{\mathrm{dQ}_{\text {cond }}}{\mathrm{dt}}=-\lambda \mathrm{A} \frac{\mathrm{dT}}{\mathrm{dx}} \\
\dot{\mathrm{Q}}_{\mathrm{conv}}=\frac{\mathrm{dQ}_{\mathrm{conv}}}{\mathrm{dt}}=\mathrm{h} \cdot \mathrm{A} \cdot \Delta \mathrm{T}(\mathrm{t}) \\
\dot{\mathrm{Q}}_{\mathrm{rad}}=\sigma \cdot \mathrm{A} \cdot \varepsilon \cdot \mathrm{F}_{1-2} \cdot\left(\mathrm{T}_{1}{ }^{4}-\mathrm{T}_{2}{ }^{4}\right)
\end{gathered}
$$

In this paper, the objective of the study is to identify the DC Motor component that has the highest temperature rise rate. This can be identified by comparing the temperature rise of the component under different load. Next, the effects of temperature rise in each component when motor running can also be discovered.

\section{Methodology}

In general, a small brush DC Motor that will be used is easy to be tested for observing the temperature rises. To be more detailed, the specifications of the small brush DC motor are being listed in Table 1 below.

Table 1: Small Brush Dc Motor Specification

\begin{tabular}{|c|c|}
\hline Specification & Detail \\
\hline Model & MY1016 \\
\hline Voltage & 240 VDC \\
\hline Rated speed & $2650 \mathrm{RPM}$ \\
\hline Rated current & $13.7 \mathrm{~A}$ \\
\hline Output & $250 \mathrm{~W}$ \\
\hline
\end{tabular}

For further information, components of brushed and brushless DC Motor can either simple or complex. For example, in the thermal term, the complex designs can be explained more by Aldo Boglietti, Jacek Jurak and Wenbo Wang [7-9]. These prove that the complex components are difficult to measure in thermal heat transfers which need to be used the different method. So, Figure 2 below shows the thermocouples that had been applied at the small DC motor. 


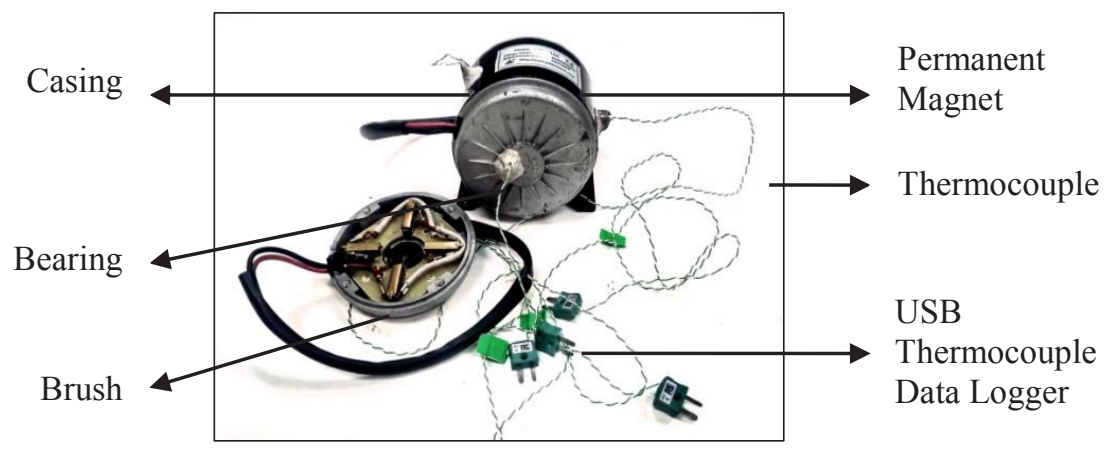

Fig.2. Component of small brush DC Motor to be measured.

Instead of presenting the thermocouples assembling, Figure 2 also highlighted the device that can be used to collect the data temperature. This device named as USB Thermocouple Data Logger which later will be connected to the Pico Log Data Logger. So, this will lead to the observation of the graph pattern for temperature rise at the monitor.

\section{Data acquisition}

Data acquisition of this experiment can be simplified by following the flowchart in Figure 3 below;

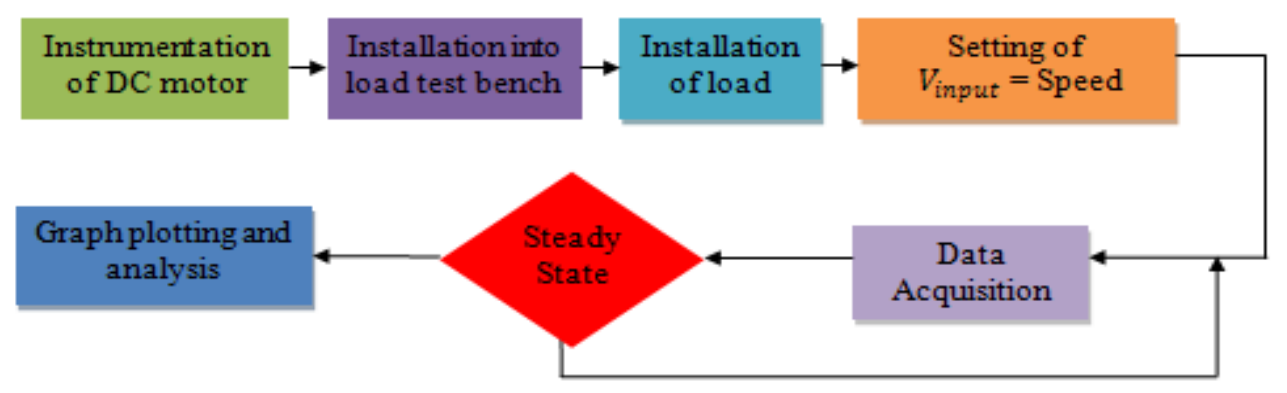

Fig. 3. Flowchart of data acquisition

Based on the flowchart above, this experiment involves seven steps. First of all, the instrumentation of the small DC motor must understand. For this step, small brush DC motor will set up by placing at the top of the test bench and also the thermocouples had been placed on each selected component. Coincidently, at the test bench contain brake disc, sprocket and chainring to form drivetrain. Thus, both small DC motor and drivetrain later will connect to each other like a bicycle application. Next, the installation into load test bench. This installation allows the load and the test bench connected to each other. This can be explained more when the load holder is built separately with the test bench. The load holder functional as the parts that cause some torque to the drivetrain. Hence, this can affect the value of the current applied. Before starting the experiment, the loads need to be installed. For the first experiment, the measurements of the temperature rises are being done without adding load and make as a reference reading. Then, the installation of loads will be repeating according to the Table 2 . 
Table 2: Weight of loads applied and current production.

\begin{tabular}{|c|c|}
\hline A weight of loads, $\mathbf{~ k g}$ & Current, A \\
\hline 0.00 & 0.7 \\
\hline 1.50 & 1.3 \\
\hline 3.50 & 3.5 \\
\hline
\end{tabular}

After that, set up the voltage of $16 \mathrm{~V}$ using U8031A Triple Output DC Power Supply for small DC motor to run. This voltage will represent the speed of the motor. Next, for data acquisition in DC motor components, the temperature rise will be recorded simultaneously by using the Pico Log Software data logger and then wait for the temperature of motor achieve the steady state before stopping the power supply. If the temperature rises are not in steady state, the process of data acquisition must be repeated. Moreover, this data logger will record the temperature rise for processes, heating, and cooling. When all the data had been collected, these data will be plotted in the graph and is analyzed according to the objectives of the experiment.

\section{Results and discussion}

\subsection{Temperature comparison between components at different load.}

The entire graphs below show the process of heating and cooling of the DC Motor components for three conditions. The main components that had been tested in the motor are brush, bearing, casing and the permanent magnet. So, from that, the temperature rises and the time taken off the motor when heating and cooling as shown in figures below can be observed. According to these figures, the graphs show the temperatures of DC Motor's components over time. To be more specified, the red colour represents the temperature rise for the brush, the blue colour for bearing, yellow colour for casing, the purple colour for permanent magnet and the green colour for the ambient temperature.

For example, Figure 6 shows the temperature rise of the motor when there is no load $(0.00 \mathrm{~kg})$ acted on it. Then, Figure 7 is when the motor running at load $1.50 \mathrm{~kg}$ and when the load at $3.50 \mathrm{~kg}$.

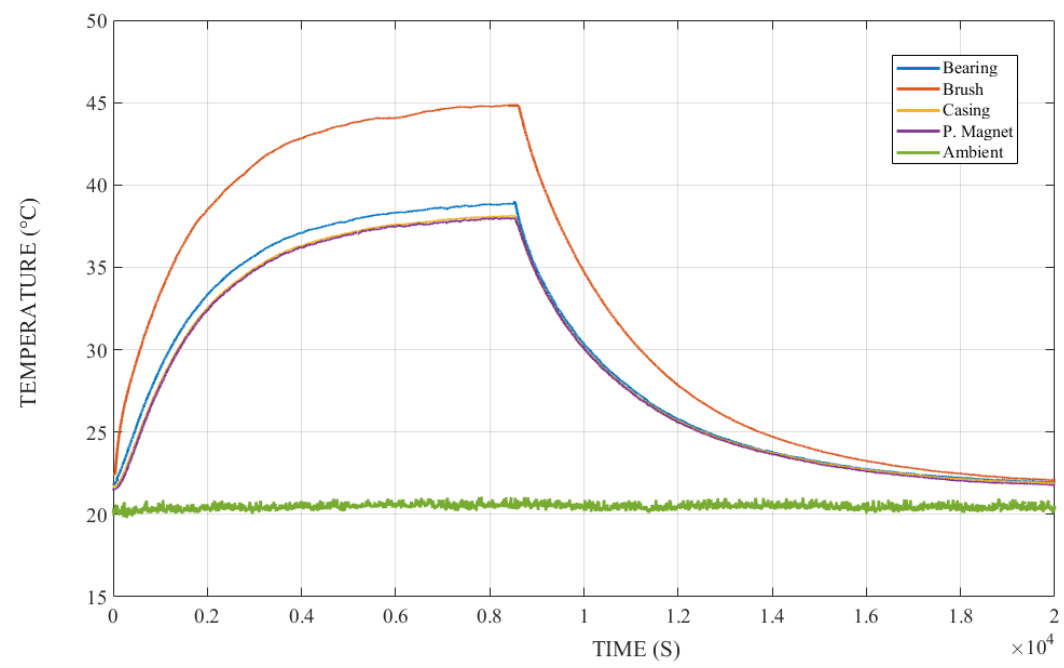

Fig. 6. Graph of temperature rise, $\mathrm{T}\left({ }^{\circ} \mathrm{C}\right)$ without load, $0.00 \mathrm{~kg}$. 


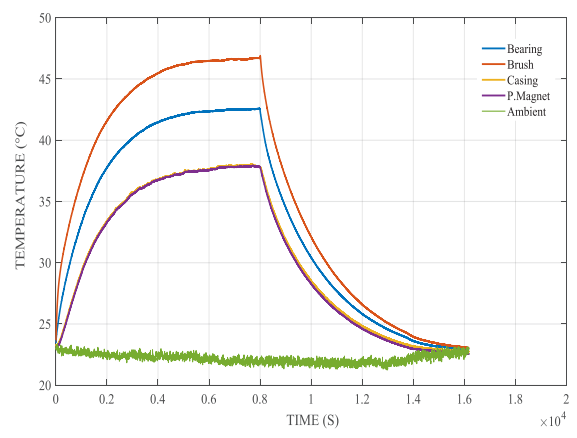

(a)

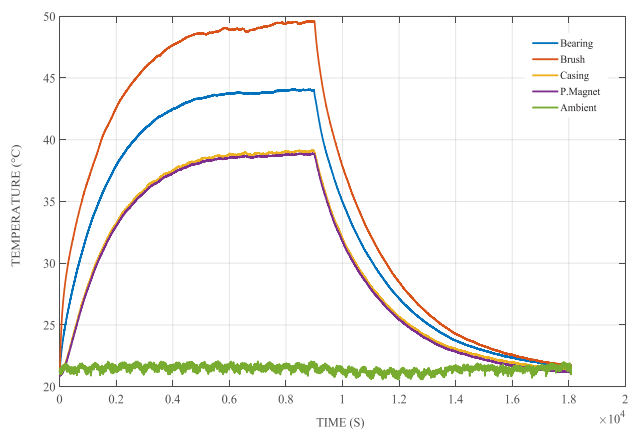

(b)

Fig. 7. (a) Graph of temperature rise $\mathrm{T}\left({ }^{\circ} \mathrm{C}\right)$ with load, $1.50 \mathrm{~kg}$ while, (b) for load, $3.50 \mathrm{~kg}$.

Based on the analysis that has been made, the graphs show the heating process took almost two hours to reach the steady state while the cooling process took another two hours to reach to ambient temperature. From the observation, obviously, the brush contains the highest temperature rise rate followed by the bearing, casing and lastly the permanent magnet. This is because; the brush is located the nearest to the commutator and also the winding. After the current flow in the motor, the winding will release some heat losses when rotating and this heat loss later will transfer to the commutator. Because of the brush contact with the commutator, the heat loss from the winding will transfer to the brush by the commutator. Hence, the brush will simultaneously be getting hot and cause the temperature to rise. Next, the bearing contains the second rate because at the bearing there is no component that can heat. It's only the friction happened that produce the heat. Besides, the temperature rise of the magnet and casing is not too high because the magnet is the closest to the casing and casing is the outermost part. So, casing in contact with air more often compares to others and has the best air circulation around it. To make it clear, the temperature differences for each component are proportional with the torque and this can be summarizing in Table 3.

Table 3: Temperature difference for each component

\begin{tabular}{|c|c|c|c|c|}
\hline \multirow{2}{*}{$\begin{array}{c}\text { A weight of the } \\
\text { load (kg) }\end{array}$} & \multirow{2}{*}{ Current, A } & \multicolumn{3}{|c|}{ Température Différence, $\Delta \boldsymbol{T}^{-}$} \\
\cline { 3 - 5 } & & $\begin{array}{c}\boldsymbol{T}_{\text {Brush }^{-}} \\
\boldsymbol{T}_{\text {Bearing }}\end{array}$ & $\begin{array}{c}\boldsymbol{T}_{\text {Bearing }} \\
\boldsymbol{T}_{\text {Casing }}\end{array}$ & $\begin{array}{c}\boldsymbol{T}_{\text {Casing }} \\
\boldsymbol{T}_{\text {Magnet }}\end{array}$ \\
\hline $\mathbf{0 . 0 0}$ & 0.70 & 5.05 & 3.25 & 0.00 \\
\hline $\mathbf{1 . 5 0}$ & 1.30 & 5.22 & 3.63 & 0.10 \\
\hline $\mathbf{3 . 5 0}$ & 3.50 & 5.44 & 4.92 & 0.24 \\
\hline
\end{tabular}

\subsection{Temperature comparison between components at different load.}

For this part, each of the components had been compared the temperature rises between the different number of loads by using the graph bar below. This due to discovering what effect the temperature rises, either the component will be heating more when adding more loads or vice versa. This part can be shown in Figure 8. From the observation, the temperature rises for each of the component are getting higher when added some load. This happened because; adding the loads can cause some torque effect to the motor when running. Hence, the current supply will increase and cause the components to heat faster. 


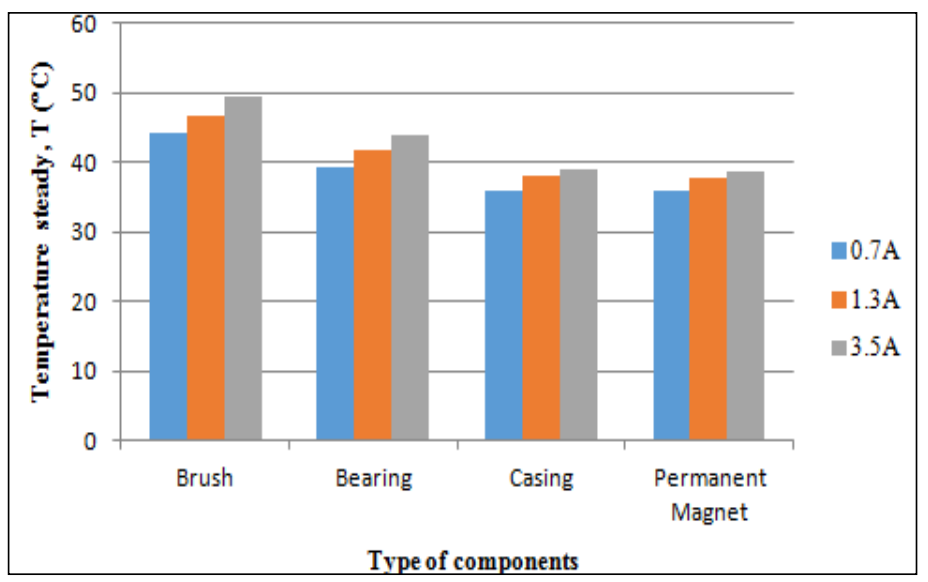

Fig. 8. Temperature steady state against the type of components under different load.

\section{Conclusions}

As a conclusion, during the experiment, the temperature rise rate of the brush is the highest followed by the bearing, casing and permanent magnet. Other than that, the main effects that can increase the temperature rise are by adding some loads to the experiment. This can be proved when the temperature difference is proportional to the load and current. Thus, regardless of the component, when the loads are being added to the experiment, the difference in temperature will increase.

UMP Research Grant (RDU 180315) supported this research. We thank our colleagues from Energy Sustainability Focus Group (ESFG) members, who provided insights and expertise that greatly assisted the research.

\section{References}

1. L. I. Van, H. Xiaoyan, F. Youtong, Int. Conf. Electr. Mach. Syst. 855 (2013).

2. D. A. Staton, M. Popescu, D. Hawkins, A. Boglietti, A. Cavagnino, 2010 IEEE Energy Convers. Congr. Expo. ECCE 2010 - Proc. 1298 (2010).

3. A. Tovar-barranco, F. Briz, A. López-de-heredia, I. Villar, 4673 (2017).

4. M. A. H. Rasid, V. Lanfranchi, K. E. K. Benkara and L. A. O. Vargas, 2013 15th European Conference on Power Electronics and Applications (EPE), Lille, 2013, pp. $1-10$.

5. M. A. H. Rasid, A. Ospina, K. El Kadri Benkara and V. Lanfranchi, 2014 International Conference on Electrical Machines (ICEM), Berlin, 2014, pp. 2199-2204.

6. M. A. H. Rasid, A. Ospina, K. E. K. Benkara and V. Lanfranchi, 2016 IEEE 25th International Symposium on Industrial Electronics (ISIE), Santa Clara, CA, 2016, pp. 134-140.

7. A. Boglietti, A. Cavagnino, D. Staton, IEEE Trans. Ind. Appl. 44, 1150 (2008).

8. J. Junak, G. Ombach, D. Staton, Design 1 (2008).

9. W. Wang, Y. Zhou, Y. Chen, 2014 17th Int. Conf. Electr. Mach. Syst. ICEMS 2014 3246 (2015) 